\title{
RHEPO FOR REDUCTION OF PERINATAL ARTERIAL STROKE: A FEASIBILITY AND SAFETY STUDY
}

\author{
M. Benders ${ }^{1}$, L. de Vries ${ }^{1}$, M. Roks ${ }^{1}$, P. Lemmers ${ }^{1}$, N. van der Aa ${ }^{1}$, I. van Straaten ${ }^{2}$, J. Smal $^{3}$, F. \\ Groenendaal ${ }^{1}, \mathrm{~F}$. van $\mathrm{Bel}^{1}$ \\ ${ }^{I}$ Neonatology, Wilhelmina Children's Hospital / UMC, Utrecht, ${ }^{2}$ Neonatology, Isala Klinieken, Zwolle, \\ ${ }^{3}$ Pediatrics, Rijnstate Ziekenhuis, Arnhem, The Netherlands
}

Background: Perinatal Arterial Stroke (PAS) occurs in 1 per 2600 newborns. No causative therapy is available. Experimental studies in a neonatal stroke model suggest neuroprotective effect of recombinant erythropoietine (rhEPO). We therefore performed a feasibilty and safety study of rhEPO in neonates with PAS.

Patients: 17 neonates with MRI-proven PAS were included, and treated with 3 subsequent doses of rhEPO of $1000 \mathrm{IU} / \mathrm{kg}$ : immediately after MRI-diagnosis of PAS and at 24 and $48 \mathrm{hrs}$ after the first dose. MRI/MRA was repeated one week and 3 months after the diagnosis of PAS. During the first weeks hemodynamic, coagulation and hematologic parameters (red cell, white cell and platelet counts), liver and renal function, and $\mathrm{Le} / \mathrm{Ri}$ regional cerebral saturation $(\mathrm{rScO} 2)$ with NIRS were monitored.

Results: HR, blood pressure and coagulation were always in the normal range, as were liver and renal functions. The table summarizes red, white and platelet counts (median and ranges). Hct's were always in the normal range. Slightly higher $\mathrm{rScO} 2$-values were detected at the infarction side.(day1-3: 0.69 [0.56-0.95] vs $0.63[0.54-0.85])$.

\begin{tabular}{|l|c|c|c|c|c|c|}
\hline & Day 1 & Day 2 & Day 3 & Day 5 & Day 7 & Day 14 \\
\hline Hct (I/I) & 0.42 & 0.44 & 0.45 & 0.44 & 0.42 & 0.39 \\
& $(0.33-0.59)$ & $(0.33-0.57)$ & $(0.35-0.64)$ & $(0.37-0.55)$ & $(0.34-0.5)$ & $(0.36-0.42)$ \\
\hline White cells & 11.2 & 12.5 & 14.7 & 18.3 & 14.8 & 11.2 \\
& $(6.9-22.1)$ & $(10.1-19.2)$ & $(10.2-22.2)$ & $(11.0-32.1)$ & $(11.3-23.5)$ & $(10.3-12.0)$ \\
\hline Platelets & 214 & 258 & 271 & 358 & 345 & 347 \\
& $(78-397)$ & $(87-468)$ & $(99-436)$ & $(101-765)$ & $(243-431)$ & $(268-406)$ \\
\hline
\end{tabular}

[table]

Conclusion: Treatment with rhEPO (1000 IU/kg daily for $3 \mathrm{~d}$ ) in neonates with PAS had no effect on red and white cell production or on platelets or coagulation. Cerebral oxygenation was higher on the infarction side. rhEPO therapy seems to be safe, but its effectivity remains to be confirmed. 